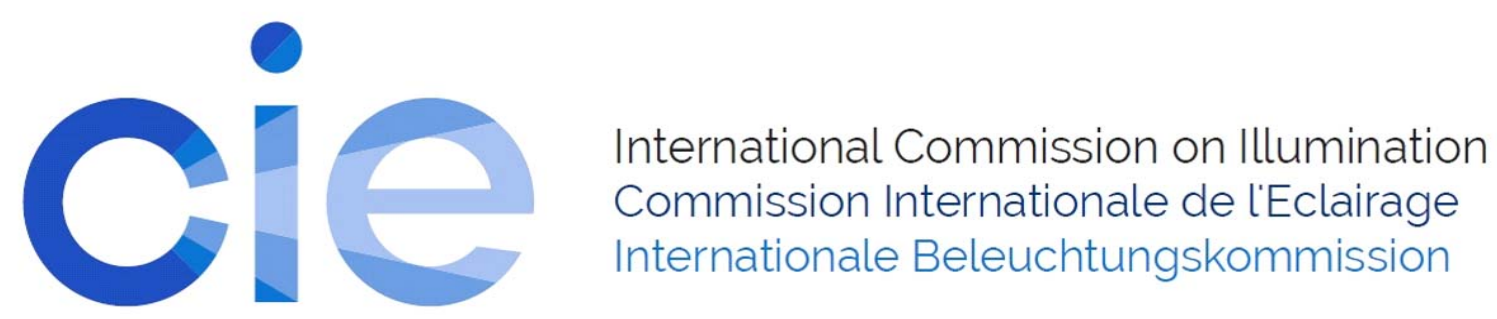

P0110

\title{
PHOTOBIOLOGICAL SAFETY OF COMMON OFFICE LIGHT SOURCES
}

\author{
Ljiljana Udovicic et al. \\ DOI 10.25039/x46.2019.PO110 \\ from \\ CIE x046:2019 \\ Proceedings \\ of the \\ 29th CIE SESSION \\ Washington D.C., USA, June 14 - 22, 2019 \\ (DOI 10.25039/x46.2019)
}

The paper has been presented at the 29th CIE Session, Washington D.C., USA, June 14-22, 2019. It has not been peer-reviewed by CIE.

(C) CIE 2019

All rights reserved. Unless otherwise specified, no part of this publication may be reproduced or utilized in any form or by any means, electronic or mechanical, including photocopying and microfilm, without permission in writing from CIE Central Bureau at the address below. Any mention of organizations or products does not imply endorsement by the CIE.

This paper is made available open access for individual use. However, in all other cases all rights are reserved unless explicit permission is sought from and given by the CIE.

CIE Central Bureau

Babenbergerstrasse 9

A-1010 Vienna

Austria

Tel.: +4317143187

e-mail: ciecb@cie.co.at

www.cie.co.at 


\title{
PHOTOBIOLOGICAL SAFETY OF COMMON OFFICE LIGHT SOURCES
}

\author{
Udovicic, L. and Janßen, M. \\ Federal Institute for Occupational Safety and Health (BAuA), Dortmund, GERMANY \\ udovicic.ljiljana@baua.bund.de
}

DOI 10.25039/x46.2019.PO110

\begin{abstract}
Light emitting diodes (LEDs) are increasingly being used for general lighting in offices and play an important role in a growing number of other applications - for instance in electronic devices as computers, laptops or smartphones. It is sometimes claimed that LEDs would be more dangerous in terms of photochemical damage to the retina (known as the blue-light hazard) than conventional light sources.

The paper presents results of blue-light hazard assessment of an LED, incandescent, halogen and compact fluorescent lamps, as well as displays of laptops and smartphones following the requirements of the Standard IEC/EN 62471 "Photobiological safety of lamps and lamp systems". It shows that in terms of their level of photobiological safety, LED lamps for general lighting are not different from conventional lamps and can be considered safe under reasonably foreseeable conditions of use. Laptop and smartphone displays pose no risk concerning the blue-light hazard.
\end{abstract}

Keywords: blue-light hazard, light emitting diodes (LEDs), general lighting, displays of electronic devices

\section{Introduction}

With the phasing out of traditional incandescent and halogen lighting in many countries, light emitting diodes (LEDs) are increasingly being used in bulbs and fixtures in offices. LEDs now predominate in other applications such as the displays in laptops, tablets or smartphones. This development is accompanied with some concerns over the photobiological safety of these new sources of LED light. In particular, their potential for a photochemical retinal damage, also called blue-light hazard, has been frequently raised in the media. This hazard has often been discussed as a hazard not applicable to traditional sources for general lighting.

The blue-light hazard is, however, not a new, previously unknown hazard. For more than 40 years it has been known that exposure to bright light may result in chemical changes in retinal cells that can lead to irreparable damage (Hunter et al., 2012). For instance, photochemically induced retinal injuries are frequently observed after a solar eclipse, due to people viewing the eclipse with the naked eye. They can also result from staring into welding arcs without proper eye protection. Photochemical retinal damage has an action spectrum known as bluelight hazard function $B(\lambda)$ with the maximum at approximately $440 \mathrm{~nm}$ (Ham and Mueller, 1976). The damage is dose dependent and cumulative in nature, i.e. it can result from exposure either to an extremely bright light for short split-second durations or a less bright light for a longer duration of perhaps a few hours.

The European Union has adopted the occupational safety and health Directive 2006/25/EC on artificial optical radiation (AORD, 2006). This Directive aims to improve the health and safety of workers by laying down exposure limit values (ELVs) to protect against optical radiation hazards. The ELVs are based on recommendations of the International Commission on Nonlonizing Radiation Protection (ICNIRP). In case of the blue-light hazard, the ELVs are based on the ICNIRP guidelines on incoherent optical radiation from 1997 (ICNIRP, 1997). In the new ICNIRP guidelines published in 2013 (ICNIRP, 2013), the recommended blue-light hazard exposure limits have not been changed. For exposure durations up to $10000 \mathrm{~s}$, the timeintegrated blue-light effective radiance $D_{\mathrm{B}}$ should not exceed $10^{6} \mathrm{~J} \cdot \mathrm{m}^{-2} \cdot \mathrm{sr}^{-1}$. For exposure du- 
rations longer than $10000 \mathrm{~s}$, the blue-light effective radiance $L_{\mathrm{B}}$ should not exceed $100 \mathrm{~W} \cdot \mathrm{m}^{-2} \cdot \mathrm{sr}^{-1}$.

Employers have to assess the level of workers' exposure to artificial optical radiation, thereby taking account of relevant European standards. Where available, manufacturer's data may be used to assist the evaluation and the implementation of the protective measures. The standard EN 62471" "Photobiological safety of lamps and lamp systems" (in Germany DIN EN 62471, 2009), harmonised under the Low Voltage Directive, provides guidance and describes measurement methods for the evaluation of photobiological hazards, including the blue-light hazard, from sources emitting incoherent optical radiation. The standard specifies a risk group classification for lamps in order to indicate their potential photobiological risk. A risk group provides information on the exposure duration for which an exposed person remains below the emission limit value of the respective group. The categories include no risk (Exempt Group), if one can be exposed to the optical radiation of a source without restriction, and high risk (Risk Group 3), if the emission limit value is already exceeded after a short-term exposure (see Table 1). The emission limit values of the risk groups have been derived from the exposure limits of the ICNIRP guidelines.

Table 1 - Risk groups according to EN 62471

\begin{tabular}{|l|l|l|}
\hline \multicolumn{1}{|c|}{ Risk group } & \multicolumn{1}{c|}{ Risk } & \multicolumn{1}{c|}{ Basis } \\
\hline $\begin{array}{l}\text { Exempt Group } \\
\text { (RG 0) }\end{array}$ & no risk & No photobiological hazard \\
\hline $\begin{array}{l}\text { Risk Group 1 } \\
\text { (RG 1) }\end{array}$ & low risk & The risk is limited by normal behavioural limitations \\
\hline $\begin{array}{l}\text { Risk Group 2 } \\
\text { (RG 2) }\end{array}$ & moderate risk & The risk is limited by the aversion response to bright light \\
\hline $\begin{array}{l}\text { Risk Group 3 } \\
\text { (RG 3) }\end{array}$ & high risk & The source may pose a risk even for momentary exposure \\
\hline
\end{tabular}

The standard defines two different measuring distances, depending on the intended use of the source: the distance in which the illuminance equals $500 \mathrm{~lx}$ for general lighting lamps and a distance of $20 \mathrm{~cm}$ for other, non-general lighting sources. The measurement requirement for evaluating the blue-light hazard takes into account the retinal image size and eye movements, using the concept of radiance being averaged over a specific field of view (FOV). The FOV that is used for the assessment is assumed to increase as the exposure duration increases. A short-duration eye exposure will result in a small area of exposure on the retina, but for longer exposure durations, eye movements are assumed to spread the radiant energy over a larger area of the retina. According to EN 62471, the measurement FOV can take values of $1,7 \mathrm{mrad}, 11 \mathrm{mrad}$ and $100 \mathrm{mrad}$. Exposure durations and blue-light hazard emission limit values of the respective risk groups are listed in Table 2.

Table 2 - Exposure durations and the blue-light hazard emission limit values of the respective risk group.

\begin{tabular}{|l|c|c|c|}
\hline & RG 0 & RG 1 & RG 2 \\
\hline Exposure duration & $t>10000 \mathrm{~s}$ & $10000 \mathrm{~s} \leq t<100 \mathrm{~s}$ & $100 \mathrm{~s} \leq t \leq 0,25 \mathrm{~s}$ \\
\hline $\begin{array}{l}\text { Emission limit value } L_{\mathrm{B}} / \\
\mathrm{W} \cdot \mathrm{m}^{-2} \cdot \mathrm{sr}^{-1}\end{array}$ & 100 & 10000 & 4000000 \\
\hline
\end{tabular}

This paper presents the photobiological safety assessment of some common office light sources according to EN 62471. The measurements for these sources will be compared with

\footnotetext{
* The standard EN 62471 is identical to IEC 62471.
} 
similar measurements for a single cold-white Diamond Dragon LED from Osram, which under certain circumstances could pose a risk for the blue-light hazard.

\section{Methods}

The spectral radiance $L(\lambda)$ was measured using a double monochromator DTM 300 (Bentham Instruments) with a cooled photomultiplier tube detector (DH-30 TE, Bentham Instruments); see Figure 1. The double monochromator has been calibrated with a $50 \mathrm{~W}$ halogen spectral radiance standard (SRS8, Bentham Instruments, traceable to a PTB standard). Fields of view of $1,7 \mathrm{mrad}, 11 \mathrm{mrad}$ and $100 \mathrm{mrad}$ have been realized with a telescope (TEL 301, Bentham Instruments). The spectral radiance was recorded with a PC and evaluated with corresponding software (BenWin+ from Bentham Instruments). The unweighted spectral radiance $L(\lambda)$ measured between $380 \mathrm{~nm}$ and $780 \mathrm{~nm}$ was weighted with the blue-light hazard function $B(\lambda)$ and integrated over the wavelength range. The experimental values $L_{\mathrm{B}, \exp }$ thus determined were compared with the respective emission limit values of the risk groups.

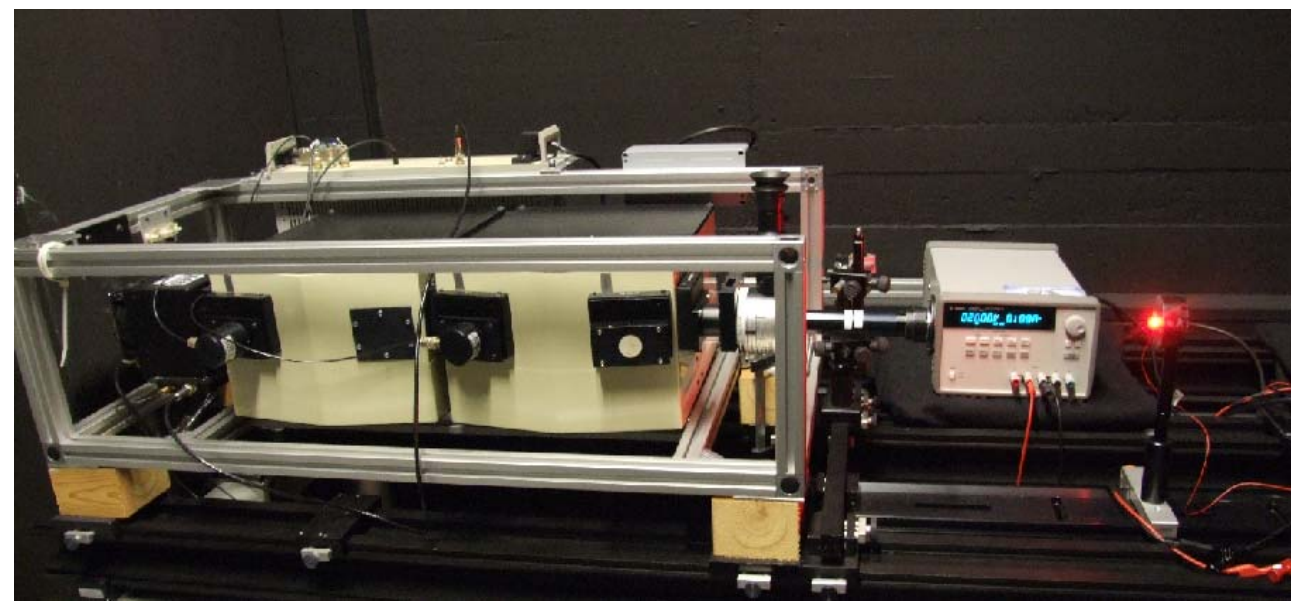

Figure 1 - Experimental setup for radiance measurements using a double monochromator with a telescope

As mentioned above, according to EN 62471 lamps for general lighting should be evaluated at a distance which produces an illuminance of $500 \mathrm{Ix}$, all other sources at a distance of $20 \mathrm{~cm}$. In this study we have compared the blue-light hazard risk of different light sources - lamps for general lighting but also electronic devices which are usually observed from a short distance. Therefore, for the sake of comparison, all sources have been evaluated at a distance of $20 \mathrm{~cm}$.

\section{Results}

The risk group classification according to EN 62471 will be described for a single cold-white LED from Osram. A Diamond Dragon LED LW W5AP of colour temperature $5600 \mathrm{~K}$ was operated with $1,4 \mathrm{~A}$. Table 3 shows the experimental values $L_{\mathrm{B}, \exp }$ measured with the field of view of $1,7 \mathrm{mrad}, 11 \mathrm{mrad}$ and $100 \mathrm{mrad}$ and the respective emission limit values of the risk groups. Since the measured values of the effective radiance exceed the emission limit values of the Exempt Group and the Risk Group 1, the LED LW W5AP is assigned to the Risk Group 2.

The permissible exposure duration $t_{\max }$ can be calculated according to

$$
t_{\mathrm{max}}=\frac{D_{\mathrm{B}, \mathrm{ELV}}}{L_{\mathrm{B}, \exp }},
$$

with $D_{\mathrm{B}, \mathrm{ELV}}=10^{6} \mathrm{~J} \cdot \mathrm{m}^{-2} \cdot \mathrm{sr}^{-1}$ and the measured blue-light effective radiance $L_{\mathrm{B}, \exp }$ corresponding to the assigned risk group (in this case $43792 \mathrm{~W} \cdot \mathrm{m}^{-2} \cdot \mathrm{sr}^{-1}$ ). The evaluated permissible expo- 
sure duration for deliberate viewing of the LED LW W5AP at a distance of $20 \mathrm{~cm}$ is $23 \mathrm{~s}$. On the one hand, this duration is long enough to set the aversion response; on the other hand, the blue-light hazard is cumulative and it is conceivable that the sum of single exposures during a working day at certain workplaces (for instance in the LED-industry or stage lighting) could exceed this exposure duration.

Table 3 - Blue-light effective radiance $L_{\mathrm{B}, \text { exp }}$ of the LED LW W5AP and die emission limit values of the risk groups. Numbers in red denote that the emission limit value of the respective risk group has been exceeded.

\begin{tabular}{|c|c|c|c|c|}
\hline İ & $\begin{array}{l}\text { Blue-light effective } \\
\text { radiance }\end{array}$ & RG 0 & RG 1 & RG 2 \\
\hline \multirow{2}{*}{$\begin{array}{l}\text { LED Diamond } \\
\text { Dragon } \\
\text { LW W5AP }\end{array}$} & $\begin{array}{l}\text { Measured value } L_{\mathrm{B}, \exp } / \\
\mathrm{W} \cdot \mathrm{m}^{-2} \cdot \mathrm{sr}^{-1}\end{array}$ & 390 & 14248 & 43792 \\
\hline & $\begin{array}{l}\text { Emission limit value } L_{\mathrm{B}} / \\
\mathrm{W} \cdot \mathrm{m}^{-2} \cdot \mathrm{sr}^{-1}\end{array}$ & 100 & 10000 & 4000000 \\
\hline
\end{tabular}

Further, we have evaluated the photobiological safety of some common office light sources the lamps for general lighting (LED, incandescent and halogen light bulbs, LED and a halogen reflector as well as a compact fluorescent lamp) and two electronic devices (a laptop and a smartphone). Compared with the LED LW W5AP, the measured values for blue-light effective radiance $L_{\mathrm{B} \text {,exp }}$ of the light sources for general lighting were at least 20 times, and in case of the two electronic devices 200000 times lower (see Figure 2 and Table 4).

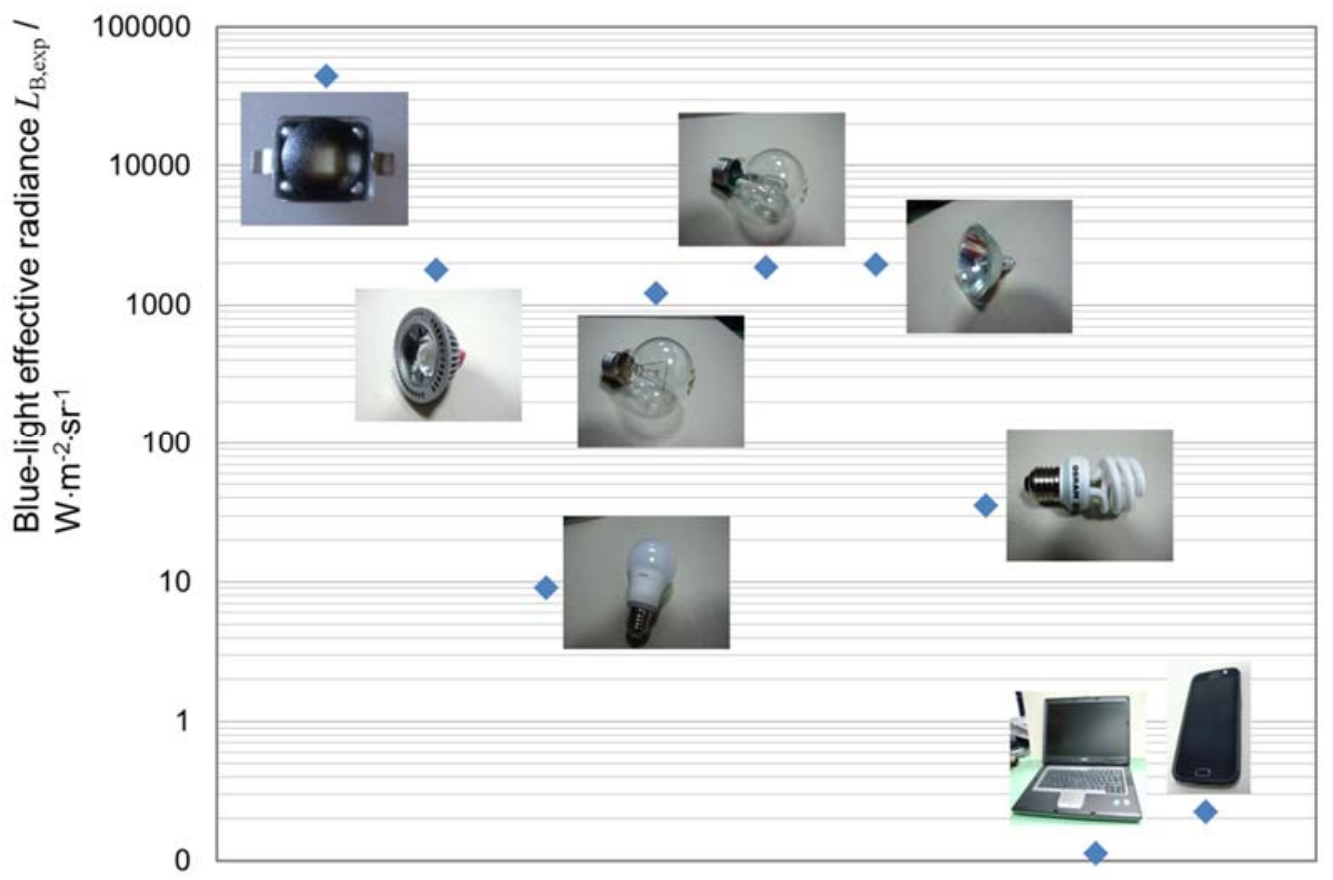

Figure 2 - Blue-light effective radiance $L_{\mathrm{B}, \mathrm{exp}}$ of the evaluated light sources.

Table 4 summarizes the results of the risk-group classification for the evaluated light sources. It shows the assigned risk group, measured blue-light effective radiance $L_{\mathrm{B}, \exp }$ and the permissible exposure duration $t_{\max }$. In terms of blue-light hazard, the lamps assessed at a distance of $20 \mathrm{~cm}$ reached at worst the Risk Group 1. A comparison of LED lamps and other conventional lamps (incandescent, halogen and compact fluorescent lamps) reveals that the risk levels are comparable.

The laptop and smartphone display were assigned to the Exempt Group and the measured blue-light effective radiance $L_{B, \exp }$ was much lower than the level known to cause photochemical retinal damage. It is interesting to compare the assessed radiance values with the corre- 
sponding value for a natural exposure. O'Hagan et al. (2016) have reported the blue-light effective radiance of the blue sky assessed for a typical clear day in June and a cloudy day in December in Chilton (UK) of $10,4 \mathrm{~W} \cdot \mathrm{m}^{-2} \cdot \mathrm{sr}^{-1}$ and $3,4 \mathrm{~W} \cdot \mathrm{m}^{-2} \cdot \mathrm{sr}^{-1}$, respectively. The measured blue-light hazard effective radiance of the laptop and smartphone display was 15 to 90 times lower.

Table 4 - Evaluated light sources assigned to a risk group, blue-light effective radiance $L_{\mathrm{B}, \mathrm{exp}}$ and the permissible exposure duration $t_{\max }$.

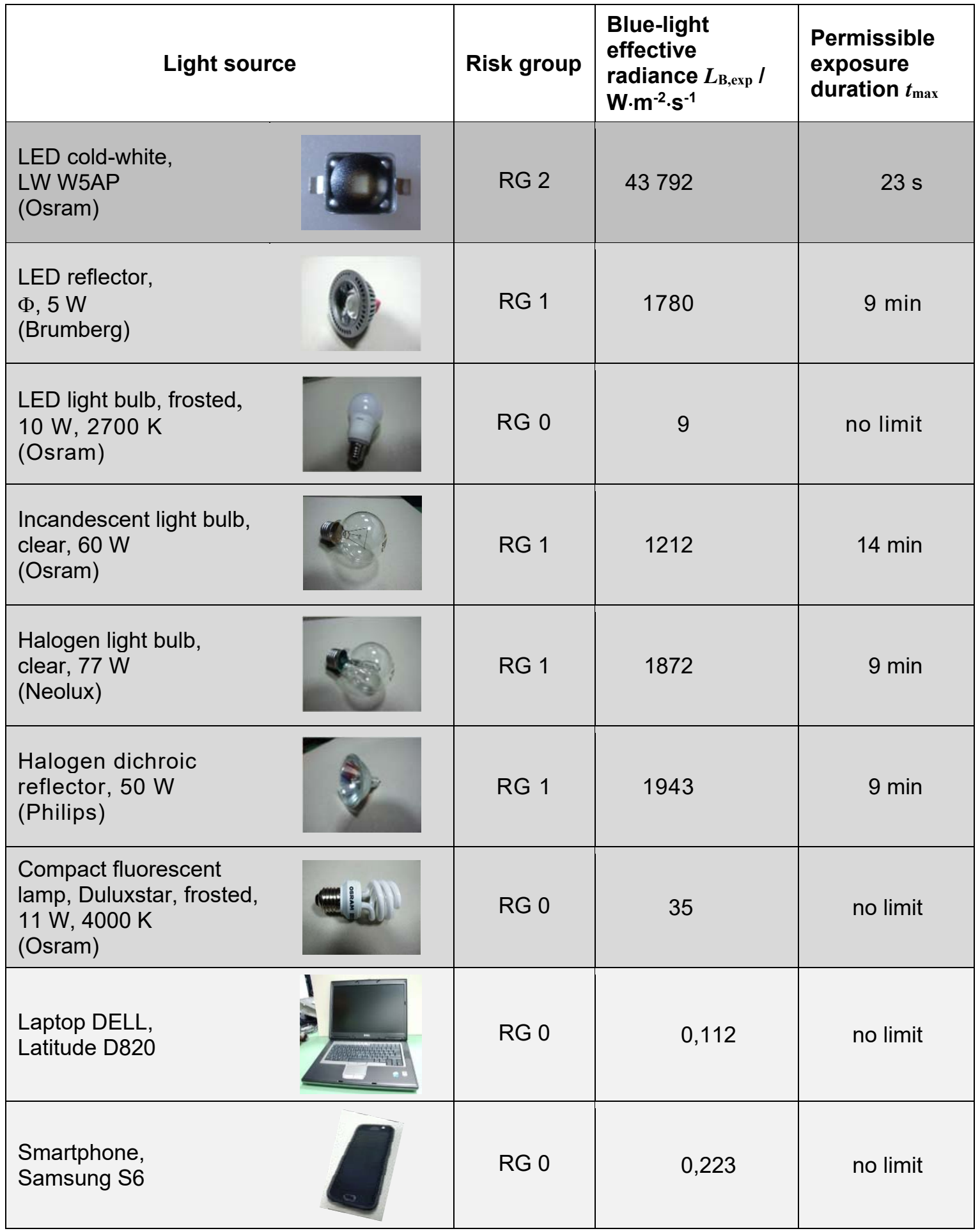




\section{Conclusion}

The aim of this study was to assess the photobiological safety of common office light sources. For the sake of comparison, the blue-light effective radiance of a bright single cold-white LED LW W5AP, which under some circumstances could pose risk for blue-light retinal hazard, was also presented. The radiance of this LED is at least one order of magnitude higher than any other radiance measured in this study.

The comparison of the remaining LED lamps to conventional lamps shows that the risk levels concerning the blue-light hazard are comparable. Therefore, in terms of their potential to cause a photochemically induced retinal injury, LED lamps used for general lighting are similar to conventional lamps and can be considered safe under normal or reasonably foreseeable conditions of use. Staring directly at a lamp for general lighting for an extended viewing time would not be considered normal behaviour.

Measured blue-light effective radiances of the laptop and a smartphone display have been much lower than the level known to cause photochemical retinal injury. Therefore, computer, laptop and smartphone displays do not pose an ocular hazard.

Our conclusion is supported by the Opinion published by the Scientific Committee on Health, Environmental and Emerging Risks (SCHEER, 2018) and the CIE Position Statement on the Blue Light Hazard (CIE, 2019).

\section{References}

AORD 2006. Directive 2006/25/EC of the European Parliament and of the Council of 5 April 2006 on the minimum health and safety requirements regarding the exposure of workers to risks arising from physical agents (artificial optical radiation) $\left(19^{\text {th }}\right.$ individual Directive within the meaning of Article 16(1) of Directive 89/391/EEC). OJ L 114, 27.4.2006, p. 38

http://eur-lex.europa.eu/legalcontent/EN/TXT/PDF/?uri=CELEX:02006L002520140101\&from $=\mathrm{EN}$

CIE 2019. CIE Position Statement on the Blue Light Hazard (April 23, 2019) http://www.cie.co.at/publications/position-statement-blue-light-hazard-april-23-2019

DIN EN 62471:2009. DIN EN 62471:2009-03; VDE 0837-471:2009-03. Photobiologische Sicherheit von Lampen und Lampensystemen (IEC 62471:2006, modifiziert); Deutsche Fassung EN 62471:2008

HAM, W.T. and Mueller H.A. 1976. Retinal sensitivity to damage from short wavelength light. Nature 260, 153-155.

HUNTER, J.J.; Morgan, J.I.W.; Merigan, W.H.; Sliney, D.H.; Sparrow, J.R. and Williams, D.R. 2012. The susceptibility of the retina to photochemical damage from visible light. Prog. Retin. Eye Res. 31(1), 28-42.

INTERNATIONAL COMMISSION ON NON-IONIZING RADIATION PROTECTION. 1997. Guidelines on Limits of Exposure to Broad-Band Incoherent Optical Radiation (0.38 to 3 $\mu \mathrm{m})$. Health Physics 73 (3), 539-554.

INTERNATIONAL COMMISSION ON NON-IONIZING RADIATION PROTECTION. 2013. Guidelines on Limits of Exposure to Incoherent Visible and Infrared Radiation. Health Physics 105(1), 74-96.

O'HAGAN, J.B.; Khazova, M. and Price, L.L.A. 2016. Low-energy light bulbs, computers, tablets and the blue light hazard. Eye 30 (2), 230-233.

SCHEER 2018. Scientific Committee on Health, Environmental and Emerging Risks (SCHEER). Opinion on Potential risks to human health of Light Emitting Diodes (LEDs) https://ec.europa.eu/health/sites/health/files/scientific_committees/scheer/docs/scheer_o -011.pdf 